\title{
Nursing Diagnoses in Promoting the Quality of Life of Patients with Crohn's Disease
}

\section{Andreza de Andrade Pinto ${ }^{1}$, Lucas Resende Aniceto ${ }^{2}$, Laurindo Pereira de Souza $^{3 *}$ and Marcia Guerino de Lima ${ }^{4}$}

${ }^{1}$ Nurse, Post-graduate Student in Nursing in Gynecology and Obstetrics at the Faculty of Biomedical Sciences of Cacoal, FACIMED, Rondônia, Brasil

${ }^{2}$ Nurse, Specialist in Intensive Care Unit Nursing from the Faculty of Biomedical Sciences of Cacoal, FACIMED, Rondônia, Brazil

${ }^{3} \mathrm{PhD}$ Student in Health Sciences at the Institute of Medical Assistance to Public Servants of the State of São Paulo-IAMSPE/SP-Brazil, Master in Health Sciences by IAMSPE/SP, and Coordinator of the Multiprofessional Residency Program in Intensive Care at Hospital Regional de Cacoal (HRC)/Rondônia, Brazil ${ }^{4}$ Obstetric Nurse, Specialist in Obstetrics and Social Obstetrics from the Faculdade da Alta Paulista-São Paulo, Professor at the Cacoal University Center-UNIFACIMED, Rondônia, Brazil

*Corresponding Author: Laurindo Pereira de Souza, PhD Student in Health Sciences at the Institute of Medical Assistance to Public Servants of the State of São Paulo-IAMSPE/SP-Brazil, Master in Health Sciences by IAMSPE/SP, and Coordinator of the Multiprofessional Residency Program in Intensive Care at Hospital Regional de Cacoal (HRC)/Rondônia, Brazil.
Received: March 03, 2021

Published: April 07, 2021

(C) All rights are reserved by Laurindo

Pereira de Souza., et al.

\section{Abstract}

Objective: To identify the basic human needs involved and to implement the nursing diagnoses to the patient with Crohn's disease, to expose the sociodemographic profile and to present the quality of life of these patients.

Methods: This is a cross-sectional and descriptive field research, with a quantitative-qualitative approach in the city of Cacoal/ Rondônia (Brazil). The sample was of the intentional type composed of 8 individuals with medical diagnosis of Crohn's disease. Data collection was performed in August 2017 through the adapted "Inflammatory Bowel Disease Questionnaire".

Results: Showed a higher prevalence in the fourth (37.5\%) and fifth (37.5\%) decades of life, female predominance (62.5\%) and white skin color (50\%). It is noted that the highest rates of poor quality of life found after applying the questionnaire are reported in emotional aspects and systemic aspects, both of which refer to $12.5 \%$ of the sample. The study found that the quality of life of Crohn's patients is classified, mainly, as good.

Conclusion: The primary nursing diagnoses in the treatment of Crohn's disease are: imbalanced nutrition, diarrhea, dysfunctional gastrointestinal motility, risk for dysfunctional gastrointestinal motility, risk of injury, impaired comfort, acute pain, disturbed sleep pattern, fatigue, anxiety, overload stress and impaired mood regulation.

Keywords: Crohn's Disease; Nursing Diagnoses; Inflammatory Bowel Disease; Nursing

Citation: Laurindo Pereira de Souza., et al. "Nursing Diagnoses in Promoting the Quality of Life of Patients with Crohn's Disease". Acta Scientific Gastrointestinal Disorders 4.5 (2021): 05-13. 


\section{Introduction}

Crohn's disease (CD) is an inflammatory bowel disease (IBD) of unknown origin that can affect any portion of the gastrointestinal tract, from the mouth to the anus. The ileum, colon and perianal region constitute the most affected portions of the digestive tract1. It is characterized by the formation and appearance of ulcerations, strictures, fistulas and granulomas. Its most common symptoms are abdominal colic, diarrhea, which can be bloody, vomiting, fever or weight loss 2 . However, CD can still include extra-intestinal manifestations such as ophthalmological, dermatological and rheumatological [1].

CD is prevalent in urban areas and industrialized countries; it is estimated that there are currently approximately 4 million Crohn's disease carriers worldwide, with 2.2 million affected individuals in Europe, and 1.4 million carriers in the United States [2]. In the last 30 years, there has been an increase in the occurrence of Crohn's disease [3]. Studies conducted in Brazil, Puerto Rico, Panama and Argentina, report an incidence around 20 to 100 patients per 100,000 inhabitants, with 1.2 to 4 new cases per 100,000 inhabitants [4].

CD has no clinical or surgical cure, and its evolution consists of periods of acute and remission ${ }^{1}$. The treatment options currently available aim at reducing inflammation, controlling symptoms, and preventing and treating complications. There is also the option that works directly with the patient's diet and lifestyle. Surgical treatment, in turn, is intended for situations where there is symptom recurrence and pharmacological treatment is not effective [5].

Due to the chronic aspect of the disease, the impact on the quality of social, professional, and family life can be significant [6]. Healthcare professionals must be aware of the extra-physical impact of the disease, the prevalent apprehensions, and the repercussions on quality of life [7]. The main objectives of nursing in the treatment involve the promotion of care and knowledge about the pathology, therapy and ways to prevent worsening [3].

The Systematization of Nursing Care (SNC) is a private activity of the nurse, who identifies health situations, providing the prescription and implementation of nursing care interventions that can favor the promotion, prevention, recovery, and rehabilitation of the individual's health [8].
Since the incidence of CD has increased worldwide, it is essential to prepare health professionals to assist patients. CD is uncommon and rare in the municipality of Cacoal/Rondônia (Brazil) and the scarcity of scientific studies related to nursing care to patients with the disease in the region makes it essential to conduct new research related to the theme.

\section{Aim of the Study}

Given the above, the study aimed to identify the basic human needs (BHN) and implement nursing diagnoses for patients with $\mathrm{CD}$, as well as to present the sociodemographic profile of patients in the city of Cacoal.

\section{Methods}

This is a cross-sectional and descriptive field research with a quantitative and qualitative approach, carried out in the municipality of Cacoal, southeastern region of Rondônia (Brazil), with patients with Crohn's disease registered in the exceptional drug program of the Health Department of the State of Rondônia. To this end, an authorization request was made to the II Regional Health Management of Cacoal, as well as a list of information for telephone contact with the patients, aiming to identify their interest in participating in the research.

The population to be studied was 14 individuals with a medical diagnosis of Crohn's disease living in the municipality of Cacoal, aged over 18 years, and the sample was intentional. However, 3 individuals refused to participate in the research, 1 patient died due to complications of Crohn's disease, and there was no response to attempt to contact 2 individuals. Therefore, respecting the inclusion or exclusion criteria, the total sample was 8 patients who agreed to participate in the research.

Data collection was performed in August 2017, through the application of a questionnaire containing a total of 41 open and closed questions, 11 of them addressing the sociodemographic variables of the participants and 30 questions referring to quality of life, acceptance of the disease, consequences, and changes in the physical, psychological, and social sectors of life of Crohn's disease patients. Part of them were adapted from the "Inflammatory Bowel Disease Questionnaire" (IBDQ) validated in a Brazilian version [9], followed by questions developed by the researchers to meet the objective of the study. 
The IBDQ is a quality of life assessment questionnaire originally composed of 32 questions covering four domains: bowel symptoms, systemic symptoms, social and emotional aspects. The answer options have seven objective alternatives, where 1 indicates the worst state of quality of life and 7, the best quality of life [10]. The questionnaire adapted for this study maintained these evaluation and classification criteria.

Afterwards, the most common complaints among the interviewees were separated in the questionnaires, and from that they were identified using the North American Nursing Diagnosis Association [11], and Nursing Interventions Classification [12]. The Nursing Diagnoses and the possible Nursing Interventions to improve the clinical picture.

The research was carried out after approval by the Research Ethics Committee of the Faculdade de Ciências Biomédicas de Cacoal - FACIMED/Rondônia(Brazil), by Opinion no․ 2,069,190. The participants were invited and, if they agreed to participate in the research, they signed the Informed Consent Form.

For the indication of the sample data, descriptive analyses were used, using mean, mode, and percentage. The information regarding the variables was evaluated and exposed through tables, charts, and graphs from the calculation of absolute values and then compared with the appropriate literature.

\section{Results}

The data in table 1 present the sociodemographic and morbid characteristics of the Crohn's disease patients interviewed. It can be observed that the population with $\mathrm{CD}$ presents an incidence starting in the third decade of life, with a higher frequency in the fourth and fifth decade, both corresponding to $37.5 \%$ each. There was a predominance of the female gender $62.5 \%$ and white skin color 50\%. Regarding education, $37.5 \%$ had completed high school and $25 \%$ had a college degree. All participants denied family history of Crohn's disease, smoking, alcoholism or other addictions, $50 \%$ claimed to have other comorbidities, among which were lactose intolerance, etiology associated with $\mathrm{CD}$, rheumatoid arthritis, optic neuritis, diabetes mellitus, and hypertension. Only $25 \%$ of the patients had to undergo surgical procedures because of CD.

The quality of life(QL) evaluation based on the questionnaire showed a relationship with intestinal symptoms, in which $25 \%$ of

\begin{tabular}{|c|c|c|}
\hline Variables & no & $\%$ \\
\hline \multicolumn{3}{|l|}{ Age group (years) } \\
\hline $30-39$ & 1 & 12,5 \\
\hline $40-49$ & 3 & 37,5 \\
\hline $50-59$ & 3 & 37,5 \\
\hline $60-69$ & 1 & 12,5 \\
\hline \multicolumn{3}{|l|}{ Sex } \\
\hline Female & 5 & 62,5 \\
\hline Male & 3 & 37,5 \\
\hline \multicolumn{3}{|l|}{ Skin color } \\
\hline White & 4 & 50,0 \\
\hline Brown & 3 & 37,5 \\
\hline Black & 1 & 12,5 \\
\hline \multicolumn{3}{|l|}{ Education } \\
\hline Elementary School & 1 & 12,5 \\
\hline Incomplete Junior High School & 1 & 12,5 \\
\hline High School & 3 & 37,5 \\
\hline Incomplete High School & 1 & 12,5 \\
\hline Higher Education & 2 & 25,0 \\
\hline \multicolumn{3}{|c|}{$\begin{array}{l}\text { Addictions (smoking, alcoholism and/ } \\
\text { or others) }\end{array}$} \\
\hline Do not have & 8 & 100,0 \\
\hline \multicolumn{3}{|l|}{ Other morbidities } \\
\hline Yes & 4 & 50,0 \\
\hline No & 4 & 50,0 \\
\hline \multicolumn{3}{|c|}{ Family history of Crohn's Disease } \\
\hline No & 8 & 100,0 \\
\hline \multicolumn{3}{|l|}{ Surgery } \\
\hline Yes & 2 & 25,0 \\
\hline No & 6 & 75,0 \\
\hline
\end{tabular}

Table 1: Sociodemographic profile of patients with CD living in the municipality of Cacoal. Rondônia, Brazil.

Source: Author's data.

patients had regular QL, 62.5\% had good QL and only $12.5 \%$ had excellent QL; in systemic symptoms $12.5 \%$ of patients had poor QL, $37.5 \%$ regular QL and 50\% had good QL; in social aspects $12.5 \%$ had regular QL, 25\% good QL and 62.5\% great QL; in emotional aspects $12.5 \%$ had poor QL, 25\% regular QL, 50\% good QL and $12.5 \%$ great $\mathrm{QL}$, as shown in figure 1 below. 
Table 1 presents 12 most frequent nursing diagnoses found ac-

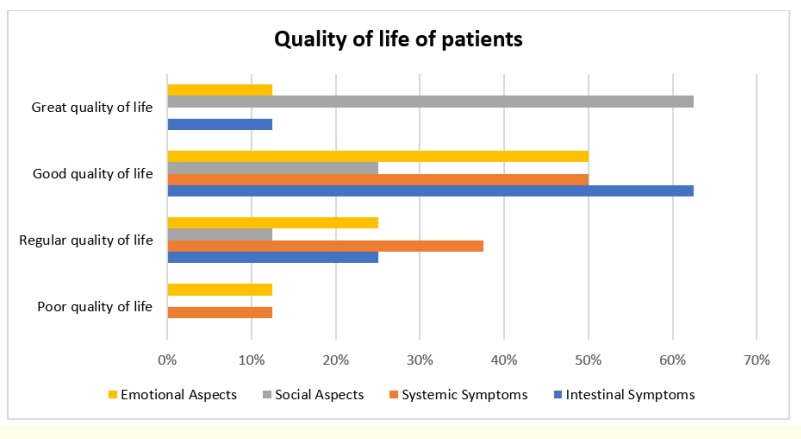

Figure 1: Distribution of the quality of life of patients through the application of the inflammatory bowel disease questionnaire (IBDQ). Rondônia, Brazil. cording to the patients' clinical conditions at the time of data collection, the nursing diagnoses were validated according to NANDA International Taxonomy II [11], and the implementation of nursing interventions selected from Nursing Interventions Classification (NIC) [12].

\section{Discussion}

According to current studies [13], the highest incidence of CD occurs between the second and third decade of life, while Santos [2], mentions a second peak of the disease between the fifth and sixth decade of life. In the present study, we obtained a peak in the fourth and fifth decade, which represents $75 \%$ of the individuals surveyed. The highest frequency of the current age of the individuals interviewed was 50 years, which represents $25 \%$ of the sur-

\begin{tabular}{|c|c|}
\hline Nursing Diagnoses & Nursing Interventions \\
\hline $\begin{array}{l}\text { Imbalanced nutrition: less } \\
\text { than body requirements }\end{array}$ & $\begin{array}{l}\text { Discuss actions with the dietician as appropriate, the amount of calories and type of nutrients needed to } \\
\text { meet the patient's nutritional requirements. Encourage safe food preparation and preservation } \\
\text { techniques. Set realistic short- and long-term goals for changing nutritional status. }\end{array}$ \\
\hline Diarrhea & $\begin{array}{l}\text { Determine the history of diarrhea. Evaluate commonly ingested medications for gastrointestinal side } \\
\text { effects. Guide patient/family members to record the volume, color, frequency, and consistency of stool. } \\
\text { Suggest a low-fiber diet. Weigh patient regularly. }\end{array}$ \\
\hline $\begin{array}{l}\text { Risk for dysfunctional } \\
\text { gastrointestinal motility }\end{array}$ & $\begin{array}{l}\text { Assess abdominal distension through physical examination. Assess for presence of diarrhea and } \\
\text { dehydration and monitor laboratory tests (e.g. electrolytes). }\end{array}$ \\
\hline Risk for injury & $\begin{array}{l}\text { Monitor for signs and symptoms of persistent bleeding (e.g. examine all secretions for live or occult } \\
\text { blood. Promote stress reduction. Avoid extremes in gastric pH level by guiding appropriate use of } \\
\text { antacids. }\end{array}$ \\
\hline Acute Pain & $\begin{array}{l}\text { Perform a thorough pain assessment (location, characteristics, onset/duration, frequency, quality, } \\
\text { intensity, and severity) noting the occurrence of nonverbal indicators of discomfort. Investigate factors } \\
\text { that relieve or worsen it. Use pain control measures before worsening and evaluate their effectiveness. } \\
\text { Check level of discomfort. Promote adequate rest to facilitate relief. }\end{array}$ \\
\hline Disturbed sleep pattern & $\begin{array}{l}\text { Adapt the environment (lighting, noise, temperature, mattress, and bed) to promote sleep. Encourage } \\
\text { the patient to establish a bedtime routine. Monitor and guide the patient to avoid food and beverages at } \\
\text { bedtime that interfere with sleep. }\end{array}$ \\
\hline Fatigue & $\begin{array}{l}\text { Determine the causes of fatigue and monitor patient for evidence of excessive physical and emotional } \\
\text { fatigue. Monitor/record patient's sleep pattern and number of hours of sleep. Provide soothing } \\
\text { diversionary activities to promote relaxation and physical activity. }\end{array}$ \\
\hline
\end{tabular}

Citation: Laurindo Pereira de Souza., et al. "Nursing Diagnoses in Promoting the Quality of Life of Patients with Crohn's Disease". Acta Scientific Gastrointestinal Disorders 4.5 (2021): 05-13. 


\begin{tabular}{|l|c|}
\hline Anxiety & $\begin{array}{c}\text { Offer real information about diagnosis, treatment, and prognosis. Encourage the expression of feelings, } \\
\text { perceptions, and fears. Provide diversionary activities aimed at reducing tension and using relaxation } \\
\text { techniques (music therapy, meditation, rhythmic breathing). Reduce or eliminate fear- or anxiety } \\
\text {-producing stimuli. }\end{array}$ \\
\hline Stress overload & $\begin{array}{c}\text { Discuss emotional experiences with the patient and investigate what triggers them. Make statements } \\
\text { of support or empathy (hug or touch). Assist patient in recognizing feelings such as anxiety, anger, and } \\
\text { sadness and encouraging them to express them. Encourage dialogue or crying as means of reducing } \\
\text { emotional response. }\end{array}$ \\
\hline Impaired mood regulation & $\begin{array}{c}\text { Regulate the level of activity and stimulation in the environment. Encourage patient to take active role } \\
\text { in treatment and recovery. Assist in identifying precipitating elements of dysfunctional mood } \\
\text { (situational stressors, physical problems). Teach new coping and problem-solving skills. }\end{array}$ \\
\hline
\end{tabular}

Table 2: Diagnoses and nursing interventions to the patient with crohn's disease.

Fonte: Herdman TH., et al. [11] and Bulechek GM., et al. [12].

veyed individuals. Regarding the age at diagnosis, the highest frequency was in the fourth decade of life, representing $37.5 \%$. The average age found at the time of diagnosis was 38.6 years, with $12.5 \%$ of the samples aged between 15 and 30 years, and $25 \%$ between 50 and 70 years at the time of diagnosis; for these researchers [3], these are periods of higher risk of developing CD.

Crohn's disease is commonly presented in white people, with a greater dominance in females, substantiating the $62.5 \%$ female samples found in this study [14]. However, $50 \%$ of the individuals are brown and black skinned, and the other half are white skinned, which shows the increasing number of cases of CD in ethnic groups that include Hispanics, blacks, and Asians [2].

Regarding the socioeconomic characterization of the interviewed patients, it was observed that the majority $37.5 \%$ have completed high school, $25 \%$ have a college degree, and a total of $37.5 \%$ have a level of education below high school. A study [15] showed that $73.1 \%$ of the individuals analyzed had attended regular school for a period longer than 8 years; in the present study, $87.5 \%$ of the individuals fit this profile, since only $12.5 \%$ said they had incomplete elementary school education.

Although smoking is related to a two-fold increased risk of developing $\mathrm{CD}$, the analysis revealed that the entire sample population does not have addictions [5]. No individual surveyed reported a family history of CD. However, a recent research ${ }^{13}$ affirms that genetic family factors predispose to a greater possibility of having the disease, and that siblings and twin pairs are genetically more susceptible.
Half of the surveyed population has comorbidities, noting that the prolonged use and high doses of corticosteroids expose patients to the risk of developing diabetes, hypertension, osteoporosis, among others [16]. $25 \%$ of the interviewed patients have hypolactasia which Silva [17] relates to the enzyme reduction and impairment of enterocytes that can be caused by intestinal diseases.

The majority $87.5 \%$ of the participants reported continuous use of medication for the maintenance of $C D$, the most common being Mesalazine 37.5\% and Azathioprine 37.5\%. Infliximab was mentioned by only one participant and only one individual showed resistance to treatment. In a study of 125 patients operated on for complications of CD, $11.2 \%$ had previously used Mesalazine, $21.6 \%$ used Azathioprine, and Infliximab had the third lowest rate of application, $4.8 \%$ [18].

Another important characteristic to be observed is the submission to surgical procedures, which Santos [19] states is necessary in cases where there is pharmacological resistance. Of the total evaluated in this study, two patients underwent surgical procedures regarding the implications of CD, and this means of treatment was a concern for $62.5 \%$ of the interviewees. Teixeira., et al. [20], verified that 42 patients with GP evolved to surgical treatment, representing $56.2 \%$ of their sample population.

A randomized study [21] describes changes in the quality of life of patients with $\mathrm{CD}$, especially in the phase of disease activity and explains that what determines the low QL are the exacerbations of

Citation: Laurindo Pereira de Souza., et al. "Nursing Diagnoses in Promoting the Quality of Life of Patients with Crohn's Disease". Acta Scientific Gastrointestinal Disorders 4.5 (2021): 05-13. 
the disease that are evidenced according to the stage of disease activity. Similarly, the samples surveyed in our analysis were entirely in remission, which represents a global variation of QL in only 6.2\% of patients.

It is noted that the highest indices of poor QL found after the application of the questionnaire are reported in emotional aspects and systemic aspects, both referring to $12.5 \%$ of the sample correlating with Souza., et al. [10], who denote these components as the main affected ones. They agree [21], reiterating that the chronicity of the disease has a great psychological and physical impact, which coincide with the literature evaluated in the study. The components of social and intestinal aspects did not show relevant results that contribute to a reduction in $\mathrm{QL}$, since all the individuals questioned in this study were in the remission phase of the disease.

Another point to be evaluated are the factors of symptom origin, which pointed out that the great elimination of gases and abdominal distension were emphasized as the main adversities faced, 25\% of the symptoms addressed. Although most of the QL of the patients surveyed was between regular $25 \%$, good $46.9 \%$ and great $21.9 \%$; $50 \%$ of the patients reported a slight increase in the frequency of bowel movements. $62.5 \%$ reported having had multiple episodes of cramps and stomach aches, and 75\% developed at least one case of diarrhea during the period evaluated. $87.5 \%$ revealed having felt nauseous sometimes while abdominal distension affected all the interviewees, presenting itself as one of the common symptoms among this population. The large elimination of gas is cited as a significant problem in $87.5 \%$ of the results.

Other symptoms of the systemic component such as tiredness, fatigue, exhaustion, and malaise, are complained about in an average of $79.2 \%$ of the answers. However, problems to get a good night's sleep and to maintain the ideal weight stand out, $75 \%$ and $87.5 \%$ respectively. At the emotional level, anxiety about the prognosis of the disease stands out, reported by all patients, while $75 \%$ describe frustration, impatience, restlessness, irritation, anger, depression or concern about the possibility of a surgical procedure as factors that lead to emotional imbalance. The lowest percentage rates of alteration evidenced by the instrument are found in the items of social aspects, where on average $41.7 \%$ of the answers refer to the deterioration of their interpersonal or social relationships propitiated by the apprehension related to the pathological disorder.
Inflammatory Bowel Diseases, such as $\mathrm{CD}$, require a multidisciplinary approach that promotes counseling, education, physical and emotional support to the patient. Patients positively evaluate the role of nurses in the treatment and emphasize the relevance of nursing intervention in the promotion of emotional support [22]. The nursing process is a tool used to guide nursing care actions, allowing the identification of problems, planning and implementation of actions, and evaluation of results [23]. Nursing processes should provide interventions that ensure relief from abdominal pain and cramps, a normal bowel movement pattern, preservation of fluid volume, nutrition and weight, anxiety reduction, and effective coping [3].

Imbalanced nutrition: less than body requirements, related to poor absorption of nutrients by the intestinal mucosa [14]. Furthermore, Rodrigues., et al. [24], state in their study that the nutritional status evaluation in patients with CD shows reduced food intake related to nausea, vomiting, abdominal pain, and restricted diets.

Diarrheal episodes are also related to the difficulty in maintaining nutrition [24]. In their literature review, modern studies [14] reiterate that these episodes are caused by several factors related to poor absorption of solutes and bile salts, abundant bacterial growth, and degradation of the mucosa, culminating in the loss of its function. These factors justify the dysfunctional gastrointestinal motility presented by these patients, resulting in great gas elimination and abdominal distension.

According to Bechara., et al. [18], in their research they point out a surgical recurrence in $29.6 \%$ of the patients evaluated, denoting higher rates of post-surgical recurrences to penetrating CD in the ileocolic and perianal regions. It also emphasizes that there is an increased risk of recurrence when the disease affects the terminal ileocolic and ileocolic regions, and the fistulizing disease is more aggressive and has a higher recurrence rate. These threats, added to the continuous use of medications, especially corticosteroids, can lead to a risk of ineffective gastrointestinal perfusion as well as risk for injury.

Abdominal pain, which usually presents as acute pain, is a very common manifestation in $\mathrm{CD}$, impairing the bearer's comfort. It arises mainly when the ileum and the cecum are affected, and is often characterized as a pain in the right lower quadrant or in the

Citation: Laurindo Pereira de Souza., et al. "Nursing Diagnoses in Promoting the Quality of Life of Patients with Crohn's Disease". Acta Scientific

Gastrointestinal Disorders 4.5 (2021): 05-13. 
epigastric region, resembling that of appendicitis [14]. Other research [25] points out, that the ingestion of sugars as well as foods with a high content of sulfur compounds may cause gastric disturbances during the inactivity of the disease, such as flatulence. It also reiterates that abdominal distension was reported by $46 \%$ of the samples, but the stage of pathological activity was not specified.

Pais [26], reinforces the importance of diet in the control of the pathology, through which it is possible to achieve the minimization of some symptoms and the correction of nutritional deficiencies, contributing to improve the quality of life of the person with CD.

In the study $75 \%$ of the interviewees reported some difficulty in sleeping, resulting in an impaired sleep pattern and $79.2 \%$ complained of tiredness, fatigue and exhaustion. These symptoms are a consequence of the gastrointestinal and nutritional alterations already mentioned and the emotional aspects of the patient, among which were identified complaints of anxiety, frustration, restlessness, irritation, anger, depression or concern with the possibility of performing a surgical procedure, leading to the Nursing Diagnoses of Anxiety, Stress Overload and Impaired Mood Regulation. A study [6] involving 50 patients with CD showed that $28 \%$ of the patients had baseline depressive mood and 56\% had anxiety symptoms. $58 \%$ of CD patients have a high incidence of mood swings, with a predominance of the disorder in females.

Living with the disease is particular and different for each individual; some take a positive attitude and develop self-care, adopting healthier habits of diet and physical activity and preventing disease complications; however, many take a negative view, as they face the need and obligation to change and adapt their habits and behaviors to their new condition [27].

It is of paramount importance that patients are observed regarding their reports on quality of life, as well as being alertly assisted by health professionals, since the negative aspects in the initial approach to the patient compromise the quality of care $[21,28]$.

\section{Conclusion}

Nursing Care Systematization is a relevant research tool for nursing professionals to carry out strategic actions aimed at promoting improvement in the patient's quality of life. The studies revealed that evaluating the nutritional patterns, life habits, and characteristic clinical presentations, such as fecal urgency or diarrhea, nausea, abdominal pain, anorexia, and weight loss, as well as the characteristics of coping with the disease, emotional and systemic alterations, are indispensable analysis criteria to dimension the impact of CD on the carrier.

This study pointed out that the quality of life of Crohn's disease patients is preponderantly classified as good quality of life, since all interviewees were in remission phase of the disease. However, among individuals who presented poor QL, the components of systemic and emotional aspects stood out with the highest percentage indices. However, more than three-fifths of this population reported having presented some of the symptoms correlated in the instrument for at least once during the surveyed period.

Through this evidence, it is concluded that the primary nursing diagnoses in the treatment of gastrointestinal disorder are: imbalanced nutrition, diarrhea, dysfunctional gastrointestinal motility, impaired sleep pattern, fatigue, anxiety, stress overload, impaired mood regulation, and impaired comfort. The NDs answer the hypothesis that the diagnoses found would correspond to the domains of nutrition, elimination and exchange, activity/rest, coping/tolerance to stress, safety/protection, and comfort, and it is essential that nursing professionals are aware of these alterations so that they can intervene and promote the advancement of quality of life for CD patients.

\section{Declaration}

The authors declare that there is no conflict of interest.

\section{Bibliography}

1. Brasil, Ministério da Saúde. "Secretaria de Atenção à Saúde". Protocolo Clínico e Diretrizes Terapêuticas da Doença de Crohn - Brasília. Editora do Ministério da Saúde (2014).

2. Santos SC. "Doença de Crohn: uma abordagem geral”. Monografia (Pós-Graduação em Análises Clínicas) - Universidade Federal do Paraná (2011): 1-47.

3. Smeltzer SO., et al. "Brunner and Suddarth: Tratado de Enfermagem Médico-Cirúrgica". 12 $2^{\text {th }}$ edition. Editora Guanabara Koogan 2 (2014): 1071-1117.

4. Vargas RD. "Epidemiología de la enfermedad inflamatoria intestinal: ¿por qué las diferencias entre Norteamérica y Latinoa- 
mérica?". Revista Colombiana de Gastroenterología 25.2 (2010): 103-105.

5. Longo DL., et al. "Medicina Interna de Harrison". $18^{\text {th }}$ edition. Porto Alegre, AMGH (2013): 2477-2495.

6. Lima FDV., et al. "Oscilação do humor em pacientes com doença de Crohn: incidência e fatores associados”. Revista Associação Médica Brasileira 58.4 (2012): 481-488.

7. O'Connor M., et al. "N-ECCO Consensus statements on the European nursing roles in caring for patients with Crohn's disease or ulcerative colitis". Journal of Crohn's and Colitis (2013): 744764.

8. Oliveira RS., et al. "Reflexões sobre as bases científicas e fundamentação legal para aplicação da sistematização do cuidado de enfermagem". Revista Uniabeu 8.20 (2015): 350-362.

9. Pontes RMA., et al. "Qualidade de vida em pacientes portadores de Doença Inflamatória Intestinal: tradução para o português e validação do questionário "Inflammatory Bowel Disease Questionnaire" (IBDQ)". Arquivos de Gastroenterologia 41.2 (2014): 137-143.

10. Souza MM., et al. "Qualidade de vida de pacientes portadores de doença inflamatória intestinal”. Acta Paulista de Enfermagem (2011): 479-484.

11. Herdman TH and Kamitsuru S. Org.Nanda International nursing diagnoses: definitions and classification, eleventh edition, 2018-2020. 11 a Ed. Porto Alegre, Artmed (2018).

12. Bulechek GM., et al. "Classificação das intervenções de enfermagem (NIC). 5aㅡ Ed. Rio de Janeiro, Elsevier (2010).

13. Lopes HL. "Doença de Crohn um desafio para os profissionais de enfermagem". [Monografia], Especialização em Doenças Crônicas não Transmissíveis, Universidade Federal de Santa Catarina, Florianópolis (2014).

14. Papacosta NG., et al. "Doença de Crohn". Revista de Patologia do Tocantins 4.2 (2017): 25-35.

15. Tavares MCM., et al. "Perfil epidemiológico e laboratorial de pacientes com diferentes formas clínicas da doença de Crohn: série de casos de um hospital regional do nordeste do Brasil". Revista de Saúde Pública de Santa Catarina, Florianópolis 9.2
(2016): 27-42.

16. Cambui YRS and Natali MRM. "Doenças inflamatórias intestinais: revisão narrativa da literatura”. Revista da Faculdade de Ciências Médicas de Sorocaba 17.3 (2015): 116-119.

17. Silva CME. "A Intolerância à Lactose e as Consequências na Absorção do Cálcio". Revista Eletrônica Atualiza Saúde 6.6 (2017): 29-35.

18. Bechara CDS., et al. "Caracterização de pacientes operados por doença de Crohn pela classificação de Montreal e identificação de fatores preditores de sua recorrência cirúrgica". Revista do Colégio Brasileiro de Cirurgiões 42.2 (2015): 97-105.

19. Santos SMR. "Doença de Crohn: Etiopatogenia, aspectos clínicos, diagnóstico e tratamento". Dissertação (Mestrado em Ciências Farmacêuticas) - Universidade Fernando Pessoa, Porto (2013).

20. Teixeira D., et al. "Doença de Crohn e cirurgia: Casuística do Serviço de Cirurgia Geral do CHAA". Revista Portuguesa de Cirurgia 32 (2015): 11-16.

21. Cohen D., et al. "Assessment of quality of life of patients with inflammatory bowel disease residing in Southern Brazil". Arquivos de Gastroenterologia 47.3 (2010): 285-289.

22. Hernández-Sampelayo P., et al. "Contribution of nurses to the quality of care in management of inflammatory bowel disease: A synthesis of the evidence". Journal of Crohn's and Colitis (2010): 611-622.

23. Souza MFG., et al. "O processo de enfermagem na concepção de profissionais de Enfermagem de um hospital de ensino". Revista Brasileira de Enfermagem, Brasília 66.2 (2013): 167-173.

24. Rodrigues SC., et al. "Aspectos nutricionais na Doença de Crohn". Cadernos da Escola de Saúde, Centro Universitário Autônomo do Brasil, Paraná 1.1 (2008).

25. Matos C., et al. "Percepção da importância e adesão ao tratamento dietético de pacientes com doença inflamatória intestinal". DEMETRA: Alimentação, Nutrição and Saúde 11.2 (2016): 459-472.

26. Pais JFC. "Doença inflamatória intestinal: influência do tabagismo, stress e depressão na qualidade de vida do doente". [Dis- 
sertaçãoMestrado], Faculdade de Psicologia e de Ciências da Educação da Universidade do Porto, Porto (2016).

27. Nobre ALM. "Aspectos psicológicos envolvidos na doença de Crohn". Revista Norte Mineira de Enfermagem 4 (Edição Especial) (2015): 79-80.

28. García-Sanjuán., et al. "Enfermedad de Crohn: experiencias de vivir con una cronicidad". Salud pública de México 58.1 (2016): 49-55.

\section{Assets from publication with us}

- Prompt Acknowledgement after receiving the article

- Thorough Double blinded peer review

- Rapid Publication

- Issue of Publication Certificate

- High visibility of your Published work

Website: www.actascientific.com/

Submit Article: www.actascientific.com/submission.php

Email us: editor@actascientific.com

Contact us: +919182824667 